\title{
Impact of microzooplankton and copepods on the growth of phytoplankton in the Yellow Sea and East China Sea
}

\author{
Wuchang Zhang $\cdot$ Hongbo Li $\cdot$ Tian Xiao · \\ Jing Zhang $\cdot$ Chaolun $\mathbf{L i} \cdot$ Song Sun
}

Published online: 18 February 2009

(C) Springer Science+Business Media B.V. 2009

\section{Erratum to: Hydrobiologia (2006) 553:357-366 \\ DOI 10.1007/s10750-005-0857-2}

The online PDF of this article contains the wrong Fig. 3 (a duplicate of Fig. 2). The correct figure is shown overleaf. (The printed version in Vol. 553 is correct.) We apologise for this error.

The online version of the original article can be found under doi:10.1007/s10750-005-0857-2.

W. Zhang $(\varangle) \cdot$ H. Li · T. Xiao · C. Li · S. Sun Key Laboratory of Marine Ecology and Environmental Sciences, Institute of Oceanology, Chinese Academy of Sciences, 7 Nanhai Road, 266071 Qingdao, People's Republic of China

e-mail: wuchangzhang@ms.qdio.ac.cn

J. Zhang

College of Chemistry and Chemical Engineering, Ocean University of China, 5 Yushan Road, 266003 Qingdao,

People's Republic of China 

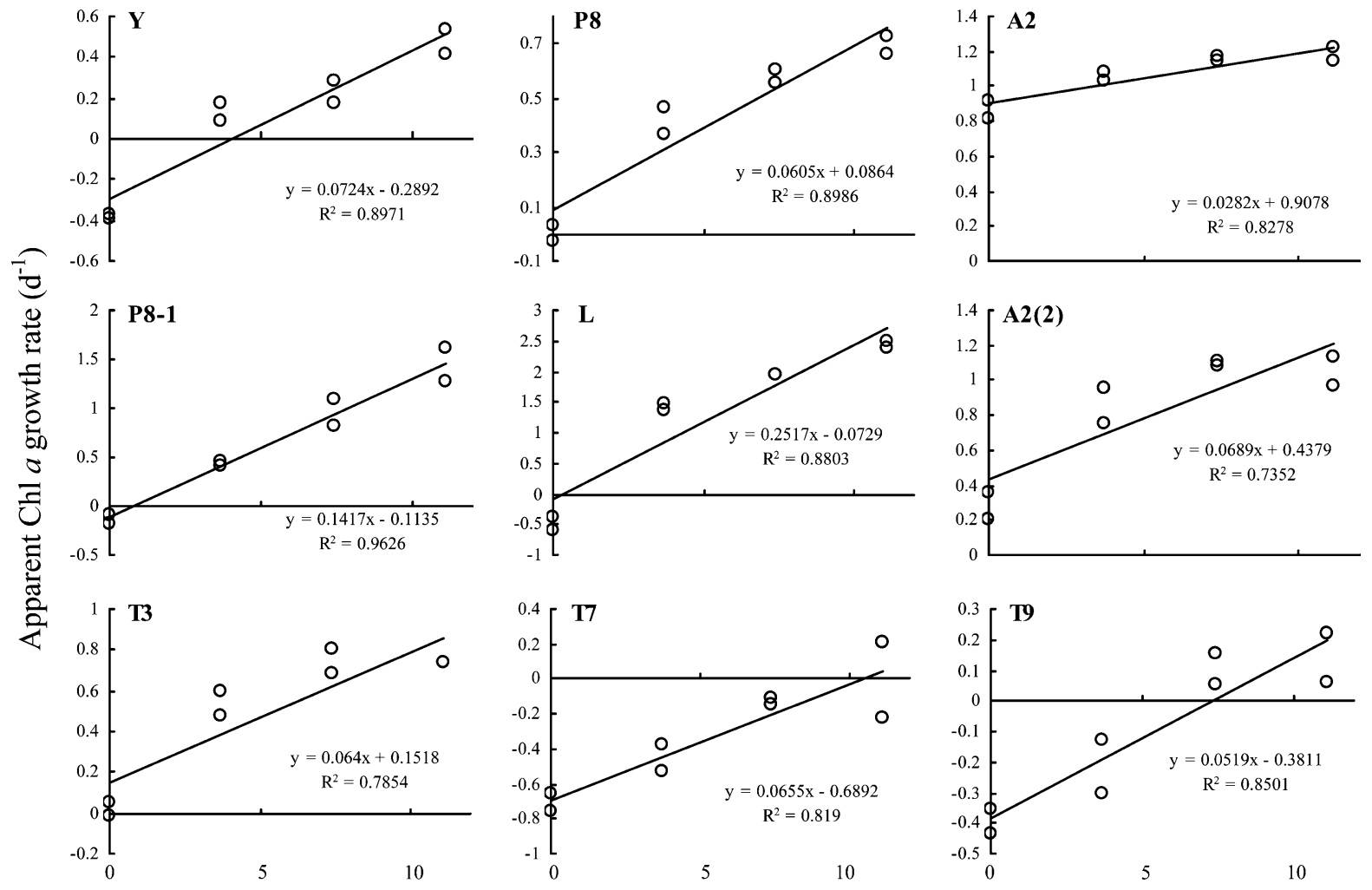

Copepod concentration (n, ind $\mathrm{l}^{-1}$ ) added

Fig. 3 The results of the copepod addition incubations. The data were regressed according to Eq. (5) 